\title{
Clinical efficacy of combined rituximab treatment in a woman with severe Graves' ophthalmopathy
}

\author{
XIAOMEI LIU ${ }^{1,2}$, HUI GUO ${ }^{1}$, JUAN LIU ${ }^{1}$ and BINGYIN SHI ${ }^{1}$ \\ ${ }^{1}$ Department of Endocrinology, First Affiliated Hospital of Xi'an Jiaotong University, Xi'an, Shaanxi 710061; \\ ${ }^{2}$ Department of Endocrinology, Nanjing First Hospital, Nanjing Medical University, Nanjing, Jiangsu 210006, P.R. China
}

Received March 3, 2015; Accepted April 11, 2016

DOI: 10.3892/etm.2016.3367

\begin{abstract}
The present study reports the case of a female Chinese patient with Graves' disease (GD) and severe Graves' ophthalmopathy (GO) in its active phase, who was treated with propylthiouracil and oral prednisolone for 2 months at a local hospital. However, a lack of improvement in symptoms meant that the patient was transferred to the First Affiliated Hospital of Xi'an Jiaotong University (Xi'an, China), whereupon the patient received high-dose intravenous methylprednisolone pulse therapy, although with limited efficacy. Subsequently, rituximab (RTX; anti-CD20 monoclonal antibody) combined with orbital irradiation treatment was initiated. The patient responded positively to the combined treatment; the clinical symptoms and enlargement of the extraocular muscles were ameliorated, and there were marked decreases in the clinical activity and NOSPECS grading scores. Furthermore, the serum levels of anti-thyrotropin receptor antibodies (TRAb) were markedly decreased at 2 months following RTX therapy. The patient was maintained in a euthyroid state by treatment with methimazole during and following RTX therapy. It was concluded that RTX treatment may attenuate severe GO by depleting lymphocytes, and may promote the recovery of GD by reducing the serum levels of TRAb.
\end{abstract}

\section{Introduction}

Graves' disease (GD) affects $1-2 \%$ of the adult population (1). The patient's quality of life decreases (2) due to the adverse metabolic effects of elevated thyroid hormone and the thyrotropin-receptor antibodies; this can affect emotional lability and sleep, and cosmetic effects such as goiter (3). Graves' ophthalmopathy (GO), which is the most common extrathyroidal manifestation of GD, is an autoimmune disorder of the

Correspondence to: Professor Bingyin Shi, Department of Endocrinology, First Affiliated Hospital of Xi'an Jiaotong University, 277 Yanta West Road, Xi'an, Shaanxi 710061, P.R. China

E-mail: shibingy@126.com

Key words: Graves' ophthalmopathy, rituximab, clinical efficacy eyes characterized by inflammation of the orbital connective tissue, inflammation and fibrosis of the extraocular muscles and adipogenesis in the eyes (4). Between $20-25 \%$ of patients with GD have clinically apparent TAO at the time of diagnosis (5). Rituximab (RTX) is a human/murine chimeric anti-CD20 monoclonal antibody whose variable (antigen-binding) region is derived from a mouse antibody (6). The binding of RTX to CD20 blocks the activation and differentiation of B-cells, since CD20 is expressed on the surface of pre-B cells and mature B lymphocytes (6). Conversely, CD20 is absent on the surface of stem cells, pro-B lymphocytes and plasma cells (7-9), such that treatment with RTX promotes the specific elimination of B-cells without affecting the regeneration of B-cells from stem cells and the production of immunoglobulins by plasma cells (6). The present study reports the case of a female Chinese patient with severe GO, who eventually recovered following RTX treatment.

\section{Case report}

A 58-year-old woman (non-smoker) was diagnosed with GD and GO in July 2013 at the First Hospital of Yulin (Yulin, China), where she received $50 \mathrm{mg}$ propylthiouracil (PTU) and $10 \mathrm{mg}$ prednisolone (Beijing Shunxin Xiangyun Pharmaceutical Co., Ltd., Beijing, China) three times daily (t.i.d.). Prednisolone was administered in decreasing doses: $30 \mathrm{mg}$ for the initial 2 weeks, $25 \mathrm{mg}$ for 1 week, $20 \mathrm{mg}$ for 7 weeks. PTU was reduced to $100 \mathrm{mg}$ daily $(25 \mathrm{mg}$ in the morning and afternoon, and $50 \mathrm{mg}$ in the evening) following a reevaluation of the patient's thyroid function in August 2013. However, a the lack of improvement in the symptoms of GO meant that the patient was transferred to the First Affiliated Hospital of Xi'an Jiaotong University (Xi'an, China) in September 2013 for further treatment.

Upon admission to the First Affiliated Hospital of Xi'an Jiaotong University, the thyroid function of the patient was normal and so PTU was replaced with $5 \mathrm{mg} /$ day methimazole (Merck KGaA, Darmstadt, Germany). An eye examination revealed extremely severe $\mathrm{GO}$, including restriction of the muscles in all directions, loss of eyesight in the right eye, reduced visual acuity in the 'counting fingers' test in the left eye, reduced light perception, proptosis (right eye, $19 \mathrm{~mm}$; left eye, $20 \mathrm{~mm}$ ), a clinical activity score (CAS) (10) of 7/7 and a NOSPECS score (11) of 6c. An orbital computed tomography 

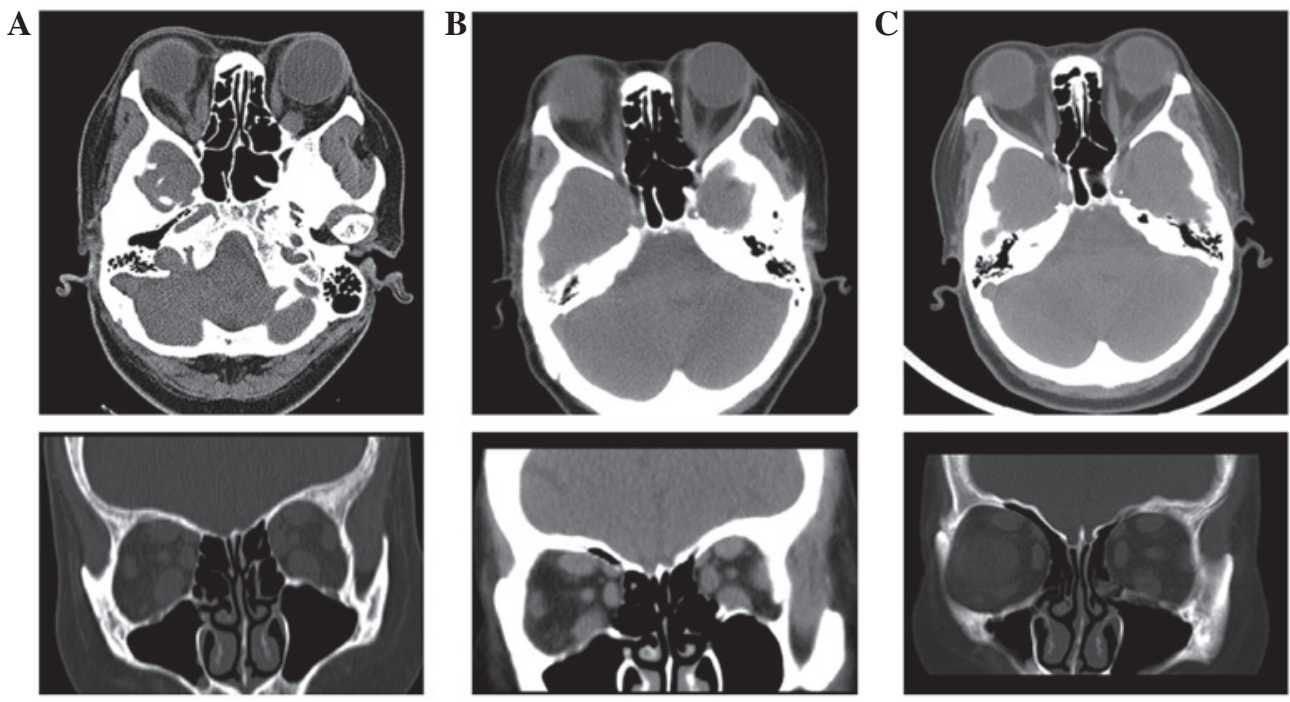

Figure 1. Changes in the orbital computed tomography (CT) scans from admission to the end of follow-up. (A) CT scans prior to rituximab (RTX) treatment on 2nd September 2013. (B) CT scans 2 months following RTX treatment (20th February 2014). (C) CT scans 5 months following RTX treatment (13th May 2014).

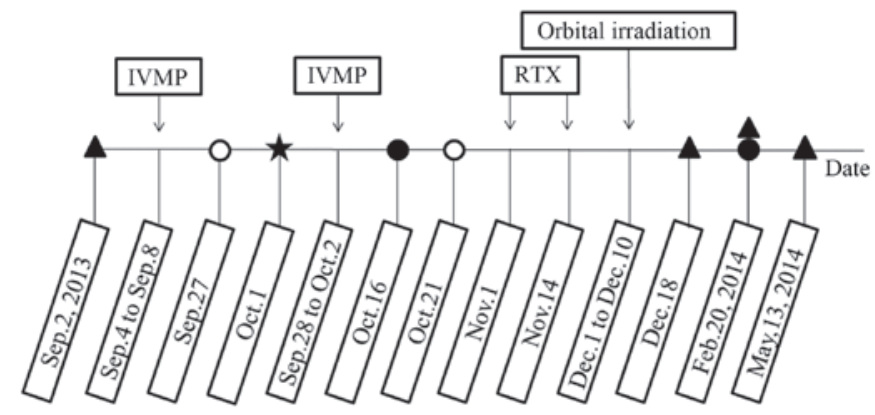

Figure 2. Treatment protocol from admission to the end of follow-up. IVMP, high-dose intravenous methylprednisolone pulse therapy; RTX, rituximab; $\circ$, oral glucose tolerance test; $\bullet$, anti-thyrotropin receptor antibodies assay (positive reference range, $>9.31$ ); $\boldsymbol{\Delta}$, orbital computed tomography scan; $\mathbf{\square}$, temporary tarsorrhaphy; $\downarrow$, administration.

(CT) scan on 2nd September 2013 showed thickening of the extraocular muscles, in particular of the inferior, superior and medial recti, although with normal optic nerves (Fig. 1). The subsequent courses of tests and treatments are shown in Fig. 2. No contraindications to high-dose intravenous methylprednisolone pulse (IVMP; Pfizer, Inc., New York, NY, USA) therapy were observed in these examinations and so the patient was administered $1 \mathrm{~g}$ intravenous (i.v.) methylprednisolone every other day (3 times in total), which was repeated 20 days later. The potential side-effects of IVMP were explained to the patient and informed consent was obtained. On 1st October 2013, the patient underwent a temporary tarsorrhaphy on the right eye for the treatment of keratohelcosis and hypophasis, and the stitches were removed when the swelling of the conjunctiva was improved. At 2 weeks following the second IVMP regime, without remarkable effect, the patient was readmitted to the First Affiliated Hospital of Xi'an Jiaotong University, whereupon RTX therapy was proposed and accepted by the patient. RTX therapy was administered on 1st and 14th November 2013. The therapeutic protocol was that used for patients with rheumatoid arthritis. Briefly, it consisted of twice i.v. infusion of $1 \mathrm{~g}$ RTX (Roche Holding AG, Basel,

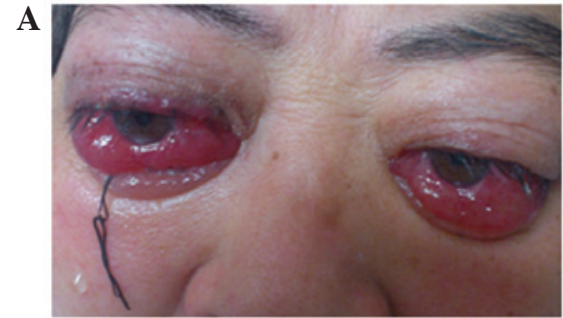

B

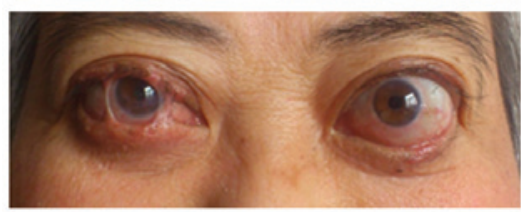

C

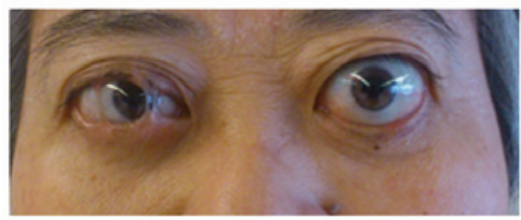

Figure 3. Changes in the appearance of the patient's eyes from before rituximab treatment to the end of follow-up. (A) Before treatment on 30th October 2013. (B) 2 months following treatment on 20th February 2014. (C) 5 months following treatment on May 13th, 2014.

Switzerland) over 255 min with a 2-week interval $(6,12)$, following pretreatment with intramuscular injection of $25 \mathrm{mg}$ Phenergan (Wellhope Pharmaceutical Co., Ltd., Shanghai, China). In addition, the patient received a $10 \mathrm{mg}$ i.v. infusion of dexamethasone during the RTX treatment. The patient did not report any side effects on the first nor second infusions. One day after the initial infusion of RTX, the methimazole was reduced to 5 and $2.5 \mathrm{mg} /$ daily, on alternate days, following reevaluation of the patient's thyroid function. Simultaneous to the RTX therapy, a cumulative dose of 20 Gy orbital irradiation was administered between 1st and 10th December 2013, with radiation fractions comprising of 2 Gy daily (Fig. 2). The results of an analysis of the serum levels of anti-thyrotropin $(\mathrm{TSH})$ receptor antibodies (TRAb; competitive 
radioimmunoassay; Human TRAb RIA kit; Medipan $\mathrm{GmbH}$, Blankenfelde-Mahlow, Germany) are also presented in Fig. 2. Secondary diabetes associated with glucocorticoid use was diagnosed using an oral glucose tolerance test (OGTT) on 27th September 2013, and $50 \mathrm{mg}$ acarbose (Bayer HealthCare AG, Leverkusen, Germany) treatment t.i.d. was initiated. The blood glucose and OGTT results were returned to normal $\sim 3$ weeks later and acarbose treatment was discontinued.

As compared with the orbital CT scan taken prior to treatment (Fig. 1), the scans taken following treatment showed signs of gradual improvements (Fig. 1). In addition, the CAS and NOSPECS scores were decreased to $1 / 7$ and $4 b$, respectively. Prior to the first infusion of RTX, the clinical features of GO were extremely severe (Fig. 3A; 30th October 2013); however, at 2 and 5 months following RTX withdrawal, the clinical features were markedly improved (Fig. 3B and C). The patient was maintained in a euthyroid state following RTX therapy by alternate treatment with 5 and $2.5 \mathrm{mg} /$ daily methimazole, which was reduced to $2.5 \mathrm{mg} / \mathrm{daily}$ in May 2014. Furthermore, the subsequent blood glucose levels were normal. The patient was satisfied with the treatment.

\section{Discussion}

The clinical symptoms of GO may include periorbital edema, lid lag and retraction, chemosis, exophthalmos and altered ocular motility (6). Severe GO may lead to exposure keratopathy, diplopia and compressive optic neuropathy, which may cause visual loss (6). The pathophysiology of GO has been shown to involve the humoral and cell-mediated immune responses (13). Existing treatment options for GO include glucocorticoids (oral or intravenous) (14), orbital radiation (15), surgical decompression (16) or a combination of these. The present study reports a novel option of immunosuppressive therapy involving RTX for the treatment of patients with severe GO.

RTX is an anti-CD20 monoclonal antibody and functions by depleting B-cells, which are precursors of the autoantibody-producing plasma cells (6). Treatment with RTX leads to specific elimination of B-cells without affecting the regeneration of $\mathrm{B}$-cells from stem cells and the production of immunoglobulins by plasma cells, since CD20 is absent from stem cells, pro-B lymphocytes and plasma cells (7-9). It has been suggested that RTX-induced transient B-cell depletion, which typically lasts for 4-6 months, may effectively modify the active inflammatory phase of GO and its subsequent clinical course (17). However, the exact mechanism underlying the effects of RTX on GO is unclear, although various hypotheses have been proposed, including the participation of B-cells, TRAb and cytokines (6).

Previous studies have reported the involvement of TRAbs in the pathogenesis of GO (18-20). A previous clinical review suggested that GO occurs as a result of immunological cross-reactivity between the thyroid and orbital tissue antigens, of which the TSH receptor is included (18). Furthermore, it was observed that hyperstimulation of the TSH receptor in the eyes leads to glycosaminoglycan secretion by pre-adipocytic fibroblasts, which subsequently increases the volume of the intraorbital tissues $(19,20)$. Previous studies have demonstrated that TRAb levels are decreased following B-cell depletion to a similar extent to that observed following treatment with methimazole or prednisolone $(17,21,22)$. The TRAb level in the present case was decreased following RTX treatment, which is consistent with the above theory and provides further rationale for the use of RTX therapy for the treatment of $\operatorname{GO}(17,21,22)$. In addition, GD has been shown to be caused by B-cell-induced production of TSH receptor-directed immunoglobulins (23), and the mechanism underlying the treatment of GO with RTX involves the depletion of B-cells (6). Therefore, there may be a potential benefit for the use of RTX therapy in the treatment of GD, which is consistent with previous studies $(24,25)$.

The potential use of RTX in GO has previously been reported in the literature (17,26-29). However, the difference and importance of the present study is that the GO of this patient was the most severe of the published cases. Furthermore, to the best of our knowledge, the present study is the first report of $\mathrm{GO}$ in a Chinese patient. Various conventional therapies were implemented during the treatment of our patient; however, the combined RTX treatment achieved satisfying efficacy and allowed the surgical procedure of orbital decompression to be avoided.

\section{Acknowledgements}

The present study was supported by the Major Project of Technological Development of Nanjing Medical University (grant no. 2015NJMUZD045).

\section{References}

1. Weetman AP: Graves' disease. N Engl J Med 343: 1236-1248, 2000.

2. Abraham-Nordling M, Törring O, Hamberger B, Lundell G, Tallstedt L, Calissendorff J and Wallin G: Graves' disease: A long-term quality-of-life follow up of patients randomized to treatment with antithyroid drugs, radioiodine, or surgery. Thyroid 15: 1279-1286, 2005.

3. Estcourt S, Vaidya B, Quinn A and Shepherd M: The impact of thyroid eye disease upon patients' wellbeing: A qualitative analysis. Clin Endocrinol (Oxf) 68: 635-639, 2008.

4. Bahn RS: Graves' ophthalmopathy. N Engl J Med 362: 726-738, 2010.

5. Burch HB and Wartofsky L: Graves' ophthalmopathy: Current concepts regarding pathogenesis and management. Endocr Rev 14: 747-793, 1993.

6. Minakaran N and Ezra DG: Rituximab for thyroid-associated ophthalmopathy. Cochrane Database Syst Rev 5: CD009226, 2013.

7. Reff ME, Carner K, Chambers KS, Chinn PC, Leonard JE, Raab R, Newman RA, Hanna N and Anderson DR: Depletion of B cells in vivo by a chimeric mouse human monoclonal antibody to CD20. Blood 83: 435-445, 1994.

8. Tsokos GC: B cells, be gone-B-cell depletion in the treatment of rheumatoid arthritis. N Engl J Med 350: 2546-2548, 2004.

9. Shen S, Chan A, Sfikakis PP, Hsiu Ling AL, Detorakis ET, Boboridis KG and Mavrikakis I: B-cell targeted therapy with rituximab for thyroid eye disease: Closer to the clinic. Surv Ophthalmol 58: 252-265, 2013.

10. Mourits MP, Koornneef L, Wiersinga WM, Prummel MF, Berghout A and van der Gaag R: Clinical criteria for the assessment of disease activity in Graves' ophthalmopathy: A novel approach. Br J Ophthalmol 73: 639-644, 1989.

11. Wiersinga WM, Smit T, Schuster-Uittenhoeve AL, van der Gaag R and Koornneef L: Therapeutic outcome of prednisone medication and of orbital irradiation in patients with Graves' ophthalmopathy. Ophthalmologica 197: 75-84, 1988.

12. Edwards JC, Szczepanski L, Szechinski J, Filipowicz-Sosnowska A, Emery P, Close DR, Stevens RM and Shaw T: Efficacy of B-cell-targeted therapy with rituximab in patients with rheumatoid arthritis. N Engl J Med 350: 2572-2581, 2004. 
13. Han R and Smith TJ: T helper type 1 and type 2 cytokines exert divergent influence on the induction of prostaglandin E2 and hyaluronan synthesis by interleukin-1beta in orbital fibroblasts: Implications for the pathogenesis of thyroid-associated ophthalmopathy. Endocrinology 147: 13-19, 2006.

14. Krassas GE, Gogakos A and Boboridis K: Corticosteroids in the medical treatment of thyroid ophthalmopathy: When and how? Somatostatin analogues: Where we stand today. Pediatr Endocrinol Rev 7 (Suppl 2): S204-S209, 2010.

15. Rajendram R, Bunce C, Lee RW and Morley AM: Orbital radiotherapy for adult thyroid eye disease. Cochrane Database Syst Rev 7: CD007114, 2012.

16. Boboridis KG and Bunce C: Surgical orbital decompression for thyroid eye disease. Cochrane Database Syst Rev 12: CD007630, 2011.

17. Salvi M, Vannucchi G, Campi I, Currò N, Dazzi D, Simonetta S, Bonara P, Rossi S, Sina C, Guastella C, et al: Treatment of Graves' disease and associated ophthalmopathy with the anti-CD20 monoclonal antibody rituximab: An open study. Eur J Endocrinol 156: 33-40, 2007.

18. Bahn RS: Clinical review 157: Pathophysiology of Graves ophthalmopathy: The cycle of disease. J Clin Endocrinol Metab 88: 1939-1946, 2003

19. Valyasevi RW, Harteneck DA, Dutton CM and Bahn RS: Stimulation of adipogenesis, peroxisome proliferator-activated receptor-gamma (PPARgamma), and thyrotropin receptor by PPARgamma agonist in human orbital preadipocyte fibroblasts. J Clin Endocrinol Metab 87: 2352-2358, 2002.

20. Cao HJ, Wang HS, Zhang Y, Lin HY, Phipps RP and Smith TJ: Activation of human orbital fibroblasts through CD40 engagement results in a dramatic induction of hyaluronan synthesis and prostaglandin endoperoxide $\mathrm{H}$ synthase-2 expression. Insights into potential pathogenic mechanisms of thyroid-associated ophthalmopathy. J Biol Chem 273: 29615-29625, 1998
21. El FD, Nielsen CH, Bonnema SJ, Hasselbalch HC and Hegedüs L: B lymphocyte depletion with the monoclonal antibody rituximab in Graves' disease: A controlled pilot study. J Clin Endocrinol Metab 92: 1769-1772, 2007.

22. Heemstra KA, Toes RE, Sepers J, Pereira AM, Corssmit EP, Huizinga TW, Romijn JA and Smit JW: Rituximab in relapsing Graves' disease, a phase II study. Eur J Endocrinol 159: 609-615, 2008.

23. Brent GA: Clinical practice. Graves' disease. N Engl J Med 358: 2594-2605, 2008.

24. Hasselbalch HC: B-cell depletion with rituximab-a targeted therapy for Graves' disease and autoimmune thyroiditis. Immunol Lett 88 $85-86,2003$.

25. Wang SH and Baker JJ: Targeting B cells in Graves' disease. Endocrinology 147: 4559-4560, 2006.

26. Salvi M, Vannucchi G, Campi I, Currò N, Simonetta S, Covelli D, Pignataro L, Guastella C,Rossi S,Bonara P,etal:Rituximab treatment in a patient with severe thyroid-associated ophthalmopathy: Effects on orbital lymphocytic infiltrates. Clin Immunol 131: 360-365, 2009.

27. Khanna D, Chong KK, Afifiyan NF, Hwang CJ, Lee DK, Garneau HC, Goldberg RA, Darwin CH, Smith TJ and Douglas RS: Rituximab treatment of patients with severe, corticosteroid-resistant thyroid-associated ophthalmopathy. Ophthalmology 117: 133. e2-139.e2, 2010

28. Mitchell AL, Gan EH, Morris M, Johnson K, Neoh C, Dickinson AJ, Perros P and Pearce SH: The effect of B cell depletion therapy on anti-TSH receptor antibodies and clinical outcome in glucocorticoid-refractory Graves' orbitopathy. Clin Endocrinol (Oxf) 79: 437-442, 2013.

29. Salvi M, Vannucchi G, Currò N, Campi I, Covelli D, Dazzi D, Simonetta S, Guastella C, Pignataro L, Avignone S and Beck-Peccoz P: Efficacy of B-cell targeted therapy with rituximab in patients with active moderate-severe Graves' orbitopathy: A randomized controlled study. J Clin Endocrinol Metab 100: 422-431, 2015. 